\title{
Avaliação das capacidades de leitura
}

\section{Reading capabilities evaluation}

\author{
Suzana dos Santos Gomes ${ }^{1}$
}

\begin{abstract}
RESUMO
Este trabalho examinou as práticas de leitura desenvolvidas pelos professores na segunda fase do Ensino Fundamental, em escolas da rede pública. Fundamentou-se nos pressupostos teóricos da enunciação e dos gêneros do discurso de Bakhtin e seu Círculo, que tomam a leitura como ato interlocutivo, implicando sempre uma compreensão responsiva ativa na construção dos sentidos. Para tanto, utilizou-se da observação participante em sala de aula e da análise contrastiva das práticas de leitura. As fontes de dados incluíram gravações, em vídeo, da rotina da sala de aula; entrevistas semiestruturadas com professores e alunos, análise dos gêneros do discurso em circulação e das práticas de leitura em sala de aula. Como postulado por Bakhtin e Volochinov (2004), a linguagem está sempre "povoada" de interações de outrem. Foi possível identificar, nos episódios em sala de aula, a coexistência de conflitos, diferentes palavras ideológicas ou linguagens sociais manifestando-se nas situações de comunicação. Os resultados destacaram a emergência de o ensino da leitura figurar em todas as disciplinas do currículo escolar os gêneros discursivos como objeto de ensino de leitura, constituindo-se como espaços de interação entre os alunos e destes com o professor.
\end{abstract}

Palavras-chave: avaliação da aprendizagem; capacidade de leitura; gêneros do discurso; ensino fundamental; currículo.

\begin{abstract}
The present research work has investigated reading practices performed by teachers at the second stage of Elementary Education in schools of the public education system. It was grounded on theoretical assumptions of enunciation and discourse genres of Bakhtin and his Circle, that consider reading as an interlocutive action, always implying an active responsive comprehension
\end{abstract}

DOI: $10.1590 / 0104-4060.46325$

1 Universidade Federal de Minas Gerais. Belo Horizonte, Minas Gerais, Brasil. Faculdade de Educação. Avenida Antônio Carlos, nº 6627. Pampulha. CEP: 31270-901. E-mail: suzanasgomes@fae.ufmg.br 
for meaning construction. For such, we have applied participant observation in the classroom and contrastive analysis of the reading practices. The data gathered include video recordings of the classroom routine; semi-structured interviews with teachers and students, an analysis of the current discourse genres in that context and of the reading practices in the classroom. As Bakhtin and Volochinov (2004) postulated, language is always "populated" by another's interactions. We could identify in the classroom episodes, the coexistence of conflicts, different ideological words or social languages manifesting themselves in the communication situations. The results highlighted the emergence for reading teaching to appear in all subjects of the school curriculum, that the discursive genres be taken as objects of reading teaching, being constituted as spaces for interaction among the students and those with the teacher.

Keywords: learning evaluation; reading capability; discourse genres; elementary education; curriculum.

\section{Introdução}

Nas últimas décadas, tem se observado uma crescente demanda pela leitura e pelo domínio da linguagem escrita em todas as áreas da vida social. Tal demanda não se restringe ao contexto brasileiro, mas diz respeito a um contexto mundial, que hoje coloca o domínio das diversas capacidades de linguagem, em especial das capacidades de leitura, como condição para acesso ao conhecimento, à participação social e ao exercício efetivo da cidadania. O domínio de tais capacidades diz respeito a tipos e níveis de letramento que vão além da decodificação da escrita, concernentes às diversas capacidades de leitura e escrita necessárias em diferentes práticas sociais.

Também nos últimos anos, com base nas políticas públicas adotadas, foram implementados programas nacionais de avaliação - Sistema Nacional de Avaliação da Educação Básica (SAEB) e Exame Nacional de Ensino Médio (ENEM) - para avaliar o rendimento dos alunos do Ensino Fundamental e do Ensino Médio. Esses exames têm demonstrado o baixo rendimento desse público e apresentam como principal causa o nível de leitura dos avaliados.

A análise dos resultados de desempenho em leitura mostra que, de maneira geral, as médias do Brasil estão abaixo do que seria aceitável. Para superar essa situação, torna-se evidente a necessidade de melhorar a qualidade dos processos de ensino-aprendizagem nas séries iniciais, pois o reflexo se dará em toda a etapa de escolarização básica. 
Esses resultados também mostram a necessidade de o ensino de Língua Portuguesa e de todas as disciplinas do currículo escolar adotarem, como eixo do trabalho docente, a construção das capacidades linguísticas entre os alunos, seja na leitura, seja na escrita. Esse eixo também é importante para orientar a qualificação dos professores e a produção de material didático para o trabalho de leitura.

No que diz respeito ao letramento em leitura, os alunos devem realizar uma ampla gama de tarefas com diferentes textos. As tarefas abrangem desde a recuperação de informações específicas até a demonstração de compreensão geral, interpretação de texto e reflexão sobre seu conteúdo e suas características. Assim, o letramento em leitura é avaliado em três dimensões: a forma do material de leitura, o modo de leitura e o uso para o qual o texto foi construído.

Os resultados, tanto do PISA quanto os do SAEB, mostram que os alunos, mesmo depois de frequentarem a escola por muitos anos, apresentam domínio limitado das capacidades necessárias para enfrentar com sucesso as atividades diversas no âmbito social. Desse modo, provocam reflexão sobre o papel da escola e o que queremos para o futuro de nossa sociedade. Esses resultados, portanto, exigem mudanças na escola e cumprimento da sua função social de preparar os alunos para a sociedade letrada contemporânea, adotando, então, práticas de leitura adequadas a contextos múltiplos e diferenciados.

Embora os resultados da aprendizagem obtidos por meio de avaliações dos sistemas de ensino demonstrem o fracasso escolar na formação de leitores, pouco se conhece sobre as práticas de leitura em todos os níveis de ensino.

No entanto, não se pode negar que várias tentativas de modificar essa realidade têm sido feitas, tanto pelas pesquisas críticas quanto pelas que propõem um instrumento alternativo do ensino da leitura, que promova o senso crítico do aluno, transformando-o num leitor ativo.

\section{Os desafios no ensino de leitura no Brasil}

Historicamente a capacidade de ler sempre foi considerada essencial à realização pessoal e, atualmente, muitos defendem a ideia de que o progresso social e econômico de um país depende muito do acesso aos conhecimentos indispensáveis, transmitidos pela palavra, seja ela impressa ou digital. E é na escola que se podem identificar evidências do crescimento do público leitor.

Rossi (2003) afirma que a crise da leitura exige que se aborde o modo como a leitura, livros e leitores vêm sendo tratados na escola. Também Fernandes (2004), ao analisar as práticas de leitura no Brasil, bem como as representações 
da escola, dos professores e do ensino na literatura infanto-juvenil a partir da década de 1980, verificou que, de modo geral, as práticas de leituras nas escolas não estão dando condições ao aluno de participarem ativamente da transformação social. Os dados ainda atestam que no Brasil não se criou uma política pública para a leitura que cuidasse também da formação do professor.

Cabe ressaltar que na pesquisa Retratos da Leitura no Brasil afirma-se que o brasileiro está lendo mais, porém, o Brasil está longe de ser um país de leitores. De acordo com a pesquisa, a escola tem importante papel na formação do leitor e é a escola que faz o Brasil ler. Assim, dos 4,7 livros lidos por habitante/ano, 3,4 , incluindo os didáticos, são indicados pela escola. Desse modo, "o Brasil está estudando e é a partir da escola que os brasileiros entram em contato com a leitura e, por meio dela, acessam os livros, independentemente de sua classe social". (LAZARO; BEAUCHAMP, 2008, p. 74). Os pesquisadores ainda afirmam que, depois da mãe, os professores são os maiores incentivadores da prática de leitura. Para melhorar o índice de leitura, é fundamental investir na capacitação do professor para esse fim.

Também a pesquisa Retratos da Leitura no Brasil (FAILLA, 2012) mostrou que os professores são os maiores influenciadores da leitura. Entre as 5 mil pessoas ouvidas em todo o Brasil, $45 \%$ apontaram os professores como tal. Essa foi a terceira pesquisa da série e, pela primeira vez, os docentes aparecem no topo da lista. O professor só pode ser incentivador da leitura se for também um leitor, posicionando-se como um sujeito que lê não apenas para buscar informações das quais necessita, como também para entrar em contato com a estética literária e ser capaz de se posicionar frente aos fatos, ideias, e às mais diversas correntes literárias.

Por todas essas razões, portanto, a leitura é importante no currículo escolar. É requisito fundamental para que o aluno exerça plenamente sua cidadania, participe da sociedade letrada em que se insere, tornando-se leitor e produtor de textos. Mesmo que o aluno não tenha que escrever livros ou gêneros de discurso complexos, certamente precisará ler muito para compreender e agir proficientemente com a linguagem. Diante disso, torna-se necessário refletir sobre as propostas nos últimos anos para se empreender a transformação significativa no ensino da leitura no Brasil.

\section{As condições de produção da pesquisa}

Esta pesquisa foi desenvolvida em uma escola da rede pública, em uma turma do $9^{\circ}$ ano da $2^{a}$ fase do Ensino Fundamental, com alunos na faixa etária 
entre 13 e 16 anos, oriundos de famílias de baixa renda. Muitos desses alunos carregam o estigma da reprovação e foram retidos em uma ou mais séries, em determinado momento da vida escolar.

A coleta de dados mediante observação participante envolveu um estudo exploratório. As fontes de dados incluíram gravações em vídeo da rotina da sala de aula; entrevistas semiestruturadas com professores e alunos, análise dos gêneros do discurso em circulação e das práticas de leitura em sala de aula.

A perspectiva da natureza dialógica da linguagem foi o alicerce teórico-metodológico em que se fundamentou a observação e a análise dos dados. Coerente com essa perspectiva, esta pesquisa objetivou conhecer as práticas de leituras desenvolvidas na $2^{\mathrm{a}}$ fase do Ensino Fundamental, bem como os gêneros discursivos em circulação. Para alcançar esse objetivo, procurou-se responder às seguintes questões: que práticas de leitura têm os alunos no contexto escolar? As interações entre professor e alunos interferem na construção de sentidos e compreensão do texto? Que capacidades de leitura os alunos mobilizaram nas Sequências Didáticas (SD)?

A proficiência em leitura demanda um processo de aprendizagem contínuo que envolve todas as disciplinas curriculares em todos os níveis de ensino. Essa constatação traz implicações concretas para os professores nos cursos de licenciatura e destaca a importância da formação no campo de letramento, de modo que os professores dominem conhecimentos linguísticos para avaliar sua concepção de leitura e repensar sua prática de ensino com os diferentes gêneros discursivos, especialmente os professores da $2^{\mathrm{a}}$ fase do Ensino Fundamental que têm uma formação voltada para a aquisição do conhecimento específico da área. Esses professores têm se deparado com um número significativo de alunos que não compreendem o que leem, fator que interfere no processo de ensino e aprendizagem, visto que a leitura é imprescindível para a construção dos conhecimentos escolares.

O trabalho com a leitura que contribua para a formação de leitores críticos demanda que o professor vá além do conhecimento do conteúdo específico da sua disciplina e estabeleça o diálogo com seus pares, visando à socialização das dificuldades enfrentadas na leitura e, consequentemente, na escrita, e busque coletivamente soluções para o desenvolvimento das capacidades lingüísticas. (GOMES, 2005; 2014).

Nesse sentido, pode-se afirmar que os procedimentos realizados em sala de aula para contemplar a leitura demandam planejamento, tendo em vista atender as reais necessidades dos alunos. Trata-se de uma ação indispensável, cuja função pedagógica é orientar, redimensionar a prática de ensino em sala de aula. 


\section{Os gêneros do discurso como objeto de ensino}

Ao longo da história humana, desenvolveram-se diferentes atividades sociais nas quais foram produzidos diferentes textos a elas adequados, os quais Bakhtin (1929/2004) chama de gêneros do discurso: "tipos relativamente estáveis de enunciados", caracterizados por um conteúdo temático, um estilo (estruturação linguística) e uma construção composicional (organização textual e relação entre locutor e interlocutor). A esse conjunto dos gêneros pode-se chamar de interdiscurso, que é teoricamente constituído de um número de gêneros infinito, já que a atividade humana, em tese, é também bastante variada.

Ainda de acordo com o autor, a natureza do enunciado caracteriza a formação histórica dos gêneros, a inter-relação entre os gêneros primários e secundários e a "correlação entre língua, ideologia e visões de mundo". (BAKHTIN, 1979, p. 282). Desconsiderar essa natureza é o mesmo que abstrair a língua de seu contexto de produção e, portanto, desviar-se da ótica que considera a língua como o instrumento de mediação.

Embasados por essa abordagem, Schneuwly e Dolz (2004) atestam que aprender a ler textos demanda a aprendizagem de "capacidades de linguagem". Também é verdade que, ao lê-los, o sujeito mobiliza seus conhecimentos. De acordo com os autores, seriam três tipos: capacidades de ação, capacidades discursivas e capacidades linguístico-discursivas.

Nesse sentido, as capacidades de linguagem são consideradas um conjunto de operações que permitem a realização de determinada ação de linguagem, instrumento para mobilizar os conhecimentos e operacionalizar a aprendizagem dos conceitos científicos. (VYGOTSKY, 1934).

Schneuwly e Dolz (2004) afirmam que o ensino de leitura deveria criar condições para o aluno: estabelecer objetivos concretos de leitura; questionar-se sobre o texto; ativar conhecimentos prévios pertinentes; recuperar as propostas explícitas; distinguir as propostas implícitas das explícitas; estabelecer a progressão temática; estabelecer inferências; revisar e verificar a coerência no curso da leitura; estabelecer relações entre o texto e o para-texto; tomar medidas para evitar os erros; utilizar macrorregras: seleção das ideias centrais; generalização; integração; escrever: tomada de notas, resumo, entre outros.

Na realidade, quando o aluno utiliza a linguagem, ele o faz, necessariamente, utilizando os gêneros em geral. Entretanto, o ensino desses gêneros deveria ser a base do trabalho de todas as disciplinas do currículo escolar porque, se o aluno for capaz de reconhecer esses instrumentos, surgirão novas possibilidades de ação que ele, certamente, conseguirá adaptar em situações particulares de comunicação. 
O conhecimento sobre o conjunto de capacidades de todas as ordens que são requeridas nas práticas de leitura vem crescendo acentuadamente com o desenvolvimento das pesquisas e teorias sobre leitura que tiveram lugar desde a segunda metade do século passado até hoje. Rojo (2009) lembra que ler envolve diversos procedimentos e capacidades.

Também Schneuwly e Dolz (2004) defendem que é papel da escola refletir sobre os aspectos sociodiscursivos, estruturais e linguísticos dos textos, criando condições para que os alunos desenvolvam capacidades de leitura e de produção de textos. Sobre as capacidades discursivas e linguísticas, os autores lembram que "toda ação da linguagem envolve diversas capacidades por parte do sujeito: adaptar-se às características do contexto e do referente (capacidades de ação); mobilizar modelos discursivos (capacidades discursivas) e dominar as operações psicolinguísticas e as unidades linguísticas (capacidades linguístico-discursivas)". (SCHNEUWLY; DOLZ, 2004, p. 74).

Nessa perspectiva, a escola tem como desafio o planejamento de situações didáticas que propiciem o desenvolvimento de capacidades de leitura diversificadas e conhecimentos apropriados para diferentes contextos. Como desenvolver, então, uma prática pedagógica que favoreça a inserção dos alunos em eventos de diferentes esferas de circulação de textos e promovam o desenvolvimento das capacidades de leitura?

Com base na vertente enunciativa, ler é dialogar com a consciência do autor, com outros enunciados e vozes, produzindo sentidos com os conhecimentos que se tem de outros textos, enunciados e as contribuições do autor. A leitura, como qualquer ato linguístico, está ligada a um propósito, desempenha uma função social, possibilitando ao leitor uma atitude responsiva diante do texto.

O processo analítico neste estudo envolveu todas as disciplinas curriculares. Tendo em vista os limites de espaço neste artigo, elegeu-se para exemplificar a análise realizada em Ciências, Geografia e Inglês.

\section{Práticas de leitura sob a ótica das capacidades}

Nesta parte, são apresentados e analisados três eventos de leitura desenvolvidos pelos professores nas Sequências Didáticas (SD) de Ciências, Geografia e Inglês. Pretende-se descrever e analisar as práticas de leitura desenvolvidas, à época da pesquisa, bem como os gêneros do discurso que fizeram parte dessas práticas. Com base nessa caracterização, buscou-se analisar o modo como os alunos realizaram as atividades de compreensão do texto. 
A escolha dessas aulas se justifica por considerar que elas ilustram o trabalho com leitura em diferentes disciplinas curriculares e apresentam evidências sobre as oportunidades de aprendizagem construídas por professores e alunos e, consequentemente, demonstram as capacidades de leitura mobilizadas pelos alunos ao longo das interações em sala de aula e das práticas de leitura implementadas.

No Quadro 1, são apresentados os eventos de leitura selecionados para análise. Esse quadro torna visível: o que se lê? - Gênero discursivo; onde se lê? - Suporte textual; como se lê? - Modos de leitura e para que se lê?

Nesse sentido, para análise dos dados, foram retomadas as concepções do Círculo de Bakhtin sobre interação, dialogismo e compreensão ativa, como também os construtos de Vygotsky sobre aprendizagem e desenvolvimento, como os conceitos de Zona de Desenvolvimento Proximal (ZDP), Mediação, dentre outros.

Vygotsky (1930), ao tratar da aprendizagem e do desenvolvimento, defende a criação de espaço no qual o aluno entra como ator de seu desenvolvimento, levando em consideração suas capacidades individuais em relação ao objeto de estudo, assim como suas potencialidades de aprendizado na interação como os pares e com o professor. Em outras palavras, com base no conceito vygotskyano de Zona de Desenvolvimento Proximal (ZDP), defende-se um ensino que atue sobre o que o aluno já sabe e nas potencialidades de seu aprendizado nas interações com o outro.

Nessa perspectiva, na metodologia de análise procurou-se compreender e descrever os processos e fenômenos discursivos, a partir de seu contexto de produção - as aulas e as interações que nela se desenvolveram - apoiando-se, também, na perspectiva enunciativa bakhtiniana, que busca considerar os sujeitos, o contexto e os fenômenos, a partir da dimensão histórica e social em que esses se inserem. Nessa medida, a linguagem foi tomada como interlocução e lugar de interação humana. Assim, foram consideradas as situações discursivas tais como ocorreram e as condições de enunciação específicas dos eventos em sala de aula.

Com base nas contribuições de Bakhtin (1929/2004), a análise desenvolvida neste estudo partiu do contexto de produção das aulas e dos enunciados que circularam; das interações produzidas pelos participantes e da descrição e análise dessas enunciações como fenômeno de ensino-aprendizagem. Coerente com essa perspectiva adotada, o foco de análise foi, principalmente, a forma como os alunos construíram os sentidos dos textos e como a interação entre professor e aluno interferiu nessas construções. (VYGOTSKY, 1930). 
QUADRO 1 - EVENTOS DE LEITURA NAS SEQUÊNCIAS DIDÁTICA DE CIÊNCIAS, GEOGRAFIA E INGLÊS

\begin{tabular}{|c|c|c|c|c|}
\hline Evento & $\begin{array}{l}\text { O que se lê? } \\
\text { Gênero do discurso }\end{array}$ & $\begin{array}{c}\text { Onde se lê? } \\
\text { Suporte textual }\end{array}$ & $\begin{array}{c}\text { Como se lê? } \\
\text { Modos de } \\
\text { leitura }\end{array}$ & $\begin{array}{c}\text { Para que se lê? } \\
\text { Objetivos da leitura }\end{array}$ \\
\hline Ciências & $\begin{array}{l}\begin{array}{l}\text { Artigo de divulgação } \\
\text { científica }\end{array} \\
\text { Textos produzidos } \\
\text { pelos alunos sobre } \\
\text { drogas }\end{array}$ & $\begin{array}{l}\text { Folha xerocopiada } \\
\text { Caderno }\end{array}$ & $\begin{array}{l}\text { Silenciosa, } \\
\text { individual e } \\
\text { coletiva }\end{array}$ & $\begin{array}{l}\text { Conhecer e refletir } \\
\text { sobre o problema das } \\
\text { drogas e suas principais } \\
\text { consequências. }\end{array}$ \\
\hline Geografia & $\begin{array}{l}\text { Unidade } 4 \\
\text { Consumo, meio } \\
\text { ambiente e } \\
\text { desigualdades no } \\
\text { espaço global }\end{array}$ & Livro didático & $\begin{array}{l}\text { Silenciosa, } \\
\text { individual e } \\
\text { coletiva }\end{array}$ & $\begin{array}{l}\text { Analisar criticamente a } \\
\text { questão do consumismo } \\
\text { e do desperdício, } \\
\text { incentivando a } \\
\text { preservação do meio } \\
\text { ambiente. } \\
\text { Avaliar a leitura e a } \\
\text { interpretação dos alunos. }\end{array}$ \\
\hline Inglês & $\begin{array}{l}\text { Depoimentos } \\
\text { dos Internautas } \\
\text { Adolescentes sobre: } \\
\text { Who I am? What do } \\
\text { I want to be when I } \\
\text { grow up? How do I } \\
\text { want the world to be } \\
\text { better when I grow } \\
\text { up? }\end{array}$ & $\begin{array}{l}\text { Site da internet: } \\
\text { www.kidlink.org }\end{array}$ & Oral e em dupla & $\begin{array}{l}\text { Ler e interpretar } \\
\text { depoimentos de } \\
\text { internautas adolescentes } \\
\text { de diferentes países } \\
\text { sobre temas de vida e } \\
\text { cidadania; } \\
\text { Participar da rede } \\
\text { mundial de cidadania em } \\
\text { prol da construção de um } \\
\text { mundo melhor }\end{array}$ \\
\hline
\end{tabular}

FONTE: Dados da pesquisa.

A análise contrastiva dos eventos de leitura nas sequências didáticas de Ciências, Geografia e Inglês aqui apresentados evidenciam as ações e discursos de professores e alunos no contexto da sala de aula. Quanto ao modo de leitura, predominaram as leituras silenciosa, individual e coletiva, acompanhadas pela professora e pelos alunos.

Em Inglês, a leitura tem uma especificidade - os alunos foram envolvidos em atividades com leitura de textos em língua estrangeira. Nessa aula, os alunos tiveram tempo de ler individualmente e em dupla, esclarecendo dúvidas com a professora e com os colegas. Nesse caso, a leitura realizada pelos alunos pode ser denominada de leitura instrumental com nível de proficiência elementar. Com a ajuda dos pares e da professora, os alunos foram capazes de compreender as ideias gerais explicitadas no texto. 
Em Geografia, a leitura foi utilizada para introdução de conteúdo do livro didático. Após a leitura de determinado trecho, a professora expôs conteúdos, discutiu aspectos considerados relevantes.

Já em Ciências, a leitura significou oportunidade para socializar textos produzidos sobre os conhecimentos adquiridos.

Geraldi (2006) critica a produção de textos na escola quando se tem o professor como único leitor, pois, nesse caso, a situação de emprego da língua é artificial. No caso da aula de Ciências, viu-se a professora ampliando o espaço de interlocução dos alunos. Também Leal e Morais (2004) lembram que na escola os alunos podem escrever para atender a finalidades diversas e se comunicar com diferentes interlocutores em situações de interação. O professor pode mediar esse processo, criando situações significativas que estimulem o aluno a ler e escrever. Portanto, o aprendizado da produção de texto, como qualquer outro, é um processo social de construção dos significados por parte do aluno, em sua interação com os textos, pessoas e situações. Nesse caso, a capacidade de reflexão sobre os textos pode ser alcançada quando o aluno lê o seu texto, mas também quando escuta a leitura dos colegas.

No que diz respeito ao gênero do discurso, observa-se que nas aulas em foco circularam diferentes gêneros. O livro didático foi utilizado em Ciências, mas não predominou nas aulas. Identificou-se a presença de quatro gêneros principais: artigo de divulgação científica, texto escolar, livro didático e o site de Internet Kidlink. Em Ciências, o artigo de divulgação científica incorporou fotos, desenhos, gráficos e charge. Já o livro didático de Geografia explorou o mapa mundi, a citação de obra literária e científica, a propaganda, as fotos e a tabela. Também em Inglês, o gênero site de internet incorporou apresentação do projeto, convite, depoimentos, fotos e desenhos de internautas.

A descrição dos gêneros que circularam nas aulas evidencia que o surgimento sempre iminente de novos gêneros discursivos no cotidiano da sociedade modifica sobremaneira a forma de relacionar-se com a leitura e a escrita. Nesse sentido, Schneuwly e Dolz (2004) lembram que a adoção de variados gêneros do discurso pode ampliar as capacidades de produção e compreensão de textos dos alunos, ajudando-os a melhor interagirem por meio da oralidade e da escrita.

Sobre as atividades de leitura realizadas pelos alunos, identificou-se participação ativa nas três aulas. Os alunos interagiram com a professora e com os colegas, participaram da discussão, atuando como sujeitos ativos no processo de compreensão dos textos.

Para Barton (1976), a interlocução típica do discurso em sala de aula é aquela concretizada na sequência de movimentos descrita como IRA (I - Iniciação da pergunta pelo professor; $\mathrm{R}$ - Resposta mecânica do aluno e A - Avaliação do professor). A frequência dessas sequências e a marcante tendência de 
professores fazerem o primeiro e o terceiro movimentos é o que torna o discurso de sala de aula tão específico.

Identificou-se um modelo de interação diferenciado. No caso de Geografia, por exemplo, a professora discutiu o conteúdo do livro didático democraticamente, aceitando as contribuições dos alunos e mostrando grande interesse na discussão do assunto com a turma. A discussão implementada na sala de aula ajudou a verificar o conhecimento sobre o assunto adquirido pelos alunos e a estabelecer ligações entre o novo conteúdo e o conhecimento em foco. Nesse sentido, os passos propostos pelo livro didático não foram seguidos rigidamente.

Em Ciências, as contribuições dos alunos, oriundas da leitura dos textos produzidos por eles, foram aceitas e discutidas, passando a fazer parte do percurso didático da professora.

Também em Inglês identificou-se uma situação de interação marcada pela confiança no professor e nos pares e, consequentemente, participação no evento de letramento. Houve colaboração, troca e independência no trabalho em dupla. O professor foi visto como um mediador disponível a quem os alunos recorreram para resolver suas dificuldades de compreensão do texto.

Pesquisas sobre estruturas participantes em sala de aula, entre elas, a de Cazden (1988) concluem que a liberdade dada aos alunos para se dirigir ao professor e aos pares é determinante da maneira como eles aprendem a pensar sobre o que leem, quanto o é a demanda cognitiva das questões apresentadas pelo professor. Nesse sentido, os dados mostram esforços dos professores na superação dos padrões rígidos de interação. À medida que os alunos constroem algum significado textual, eles participam da aula, deixam de resistir às tarefas e vão se envolvendo nas atividades em sala de aula com maior interesse.

Quanto ao aspecto prática de ensino implementada pelo professor, nas S.D as professoras atuaram como mediadoras do processo ensino-aprendizagem. Apoiando-se no processo do aluno, esse aspecto favoreceu a discussão, criou ambiente de escuta recíproca e de discussão. A metodologia adotada revelou uma postura menos diretiva, que contemplou o aluno como ser pensante, crítico e, desse modo, contribuindo para a criação de situações plurais de significados do texto.

Por sua função mediadora, o professor é figura determinante na construção das relações entre os alunos e a cultura na escola. No entanto, para que a produção dessas relações se dê no sentido de uma aproximação duradoura entre os alunos e os objetos culturais (textos) é fundamental que as circunstâncias em que se engendram tais relações sejam favoráveis, tanto à constituição de professores-leitores quanto à formação de alunos-leitores.

Sob a perspectiva bakhtiniana, ler é compartilhar vozes, é dialogar com outras possibilidades. Na escola, o leitor-professor pode compartilhar com 
o leitor-aluno suas histórias de leituras. (BAKHTIN, 1975). Se o professor compartilha um texto e visualiza que a leitura desse texto, na verdade, é um diálogo entre vozes, pode explorar esse texto como portador e representante de um discurso em determinado contexto social-histórico-político, com uma possibilidade de olhar, movimento e interlocução na interação com o aluno.

Nessa perspectiva, ao desenvolver o letramento dos alunos, o professor estará dirigindo o trabalho para práticas que visem à capacidade de utilizar a leitura e a escrita para enfrentar os desafios da vida em sociedade e de fazer uso do conhecimento adquirido para continuar aprendendo ao longo da vida.

A Tabela 1 contém dados das S.D e fornece uma representação contrastiva das capacidades que predominaram em Ciências, Geografia e Inglês. Para essa categorização utilizou-se as contribuições de Rojo (2009).

TABELA 1 - CAPACIDADES DE LEITURA ENSINADAS/APRENDIDAS NAS SEQUENNCIAS DIDÁTICAS

\begin{tabular}{l|c|c|c|c|c|c|c|c}
\hline \multicolumn{1}{c|}{ CAPACIDADES DE LEITURA } & \multicolumn{2}{|c|}{ CIÊNCIAS } & \multicolumn{2}{|c|}{ GEOGRAFIA } & \multicolumn{2}{|c|}{ INGLÊS } & \multicolumn{2}{|c}{ TOTAL } \\
\hline Capacidades de Compreensão & $\mathbf{N}^{\circ}$ & $\%$ & $\mathbf{N}^{\circ}$ & $\mathbf{\%}$ & $\mathbf{N}^{\circ}$ & $\mathbf{\%}$ & $\mathbf{N}^{\circ}$ & $\%$ \\
\hline Comparação de informações & 5 & 62,5 & 7 & 87,5 & - & - & 12 & 150,00 \\
\hline Produção de inferências globais & 3 & 37,5 & - & - & - & - & 3 & 37,5 \\
\hline Checagem de hipóteses & 2 & 28,57 & - & - & - & - & 2 & 25,00 \\
\hline Ativação conhecimentos prévios & - & - & 3 & 37,5 & 3 & 37,5 & 6 & 75,00 \\
\hline Produção de inferências locais & - & - & - & - & 3 & 37,5 & 3 & 37,5 \\
\hline Localização de informações & - & - & 3 & 37,5 & - & - & 3 & 37,5 \\
\hline $\begin{array}{l}\text { Capacidades de apreciação e } \\
\text { réplica do leitor ao texto }\end{array}$ & $\mathbf{N}^{\circ}$ & $\%$ & $\mathbf{N}^{\circ}$ & $\%$ & $\mathbf{N}^{\circ}$ & $\%$ & $\mathbf{N}^{\circ}$ & $\%$ \\
\hline $\begin{array}{l}\text { Elaboração de apreciações a valores } \\
\text { éticos e políticos }\end{array}$ & 2 & 28,37 & 3 & 42,85 & - & - & 5 & 71,22 \\
\hline $\begin{array}{l}\text { Recuperação do contexto de } \\
\text { produção do texto }\end{array}$ & - & - & - & - & 3 & 42,85 & 3 & 42,85 \\
\hline $\begin{array}{l}\text { Definição de finalidades e metas da } \\
\text { atividade de leitura }\end{array}$ & - & - & - & - & 2 & 28,57 & 2 & 28,57 \\
\hline
\end{tabular}

FONTE: Dados da pesquisa.

Esse consolidado explicita algumas evidências sobre as oportunidades de aprendizagem na leitura vivenciada no contexto da sala de aula. Como visto, predominou no âmbito das capacidades de compreensão, a capacidade de comparação de informações com 150\% de predomínio em Ciências e Geografia, dado que evidencia estímulo à leitura crítica e ampliação da compreensão leitora. 
Uma análise contrastiva do quadro também revela que não houve uma capacidade presente nas três disciplinas, ou seja, foram identificadas capacidades, oscilando em duas ou em apenas uma disciplina.

Em seguida, com 75\%, destacam-se a capacidade de ativação de conhecimentos de mundo e produção de inferências locais com $75 \%$ de presença nas S.D de Geografia e Inglês. Estreitamente interligadas, essas capacidades foram importantes no processo de contextualização do texto, ou seja, as palavras não estão soltas no texto: adquirem sentidos e significados quando são compreendidas pelos alunos no evento de leitura.

No âmbito das capacidades de apreciação e réplica do leitor em relação ao texto, identificou-se, nas S.D de Ciências e Geografia, a capacidade de percepção elaboração de apreciações relativas a valores éticos elou políticos, com $71,22 \%$, provavelmente em razão dos gêneros do discurso intercalados presentes inicialmente no artigo de divulgação científica sobre as drogas e no livro didático de Geografia. Nas discussões e nas leituras dos alunos, o tema em foco foi abordado e sua presença identificada em diferentes linguagens e esferas - por exemplo, televisiva, jornalística, escolar, publicitária, dentre outras.

Outro percentual expressivo foi identificado na S.D de Inglês; com 42,85\% aparece em destaque a capacidade de recuperação do contexto de produção do texto, considerada fundamental para que os alunos pudessem ativar conhecimentos prévios, realizar inferências globais, acionar conhecimentos de mundo e, assim, compreender globalmente depoimentos na língua estrangeira Inglês.

\section{Considerações finais}

Este estudo, desenvolvido à luz da teoria da enunciação bakhtiniana, teve como objetivo investigar as práticas de leitura na $2^{\mathrm{a}}$ fase do Ensino Fundamental. Para alcançar esse objetivo, procurou-se, neste trabalho, responder às seguintes questões: que práticas de leitura têm os alunos no contexto escolar? As interações entre professor e aluno e entre os alunos interferem na construção de sentidos e compreensão do texto? Que capacidades de leitura os alunos mobilizaram nas S.D?

Assim, as mudanças almejadas no campo da leitura demandam nova visão no ensino e nas práticas de leitura, sem as quais não há construção e cidadania. Os resultados dos alunos nas avaliações provocam reflexões sobre a adoção de procedimentos de leitura que contribuam para a superação do fracasso escolar. Constata-se a relevância da questão e por isso defende-se o aprendizado da 
leitura e o acesso a uma formação que dê ao aluno possibilidades de praticar na escola e na vida o que é próprio do ser humano: a atitude responsiva ativa.

Nesse sentido, é importante destacar que a teoria bakhtiniana leva em conta não somente as vozes sociais, mas também as individuais. Assim, um discurso pode ser tanto o lugar de encontro de pontos de vista de locutores imediatos como de visões de mundo, de orientações teóricas, de tendências filosóficas, etc. Ao considerar tanto o social como o individual, a proposta bakhtiniana permite examinar, do ponto de vista das relações dialógicas, os fenômenos do discurso cotidiano e as intenções de admiração, ironia, apreciação, reprovação, etc. Assim, todos os fenômenos presentes na comunicação real podem ser analisados à luz das relações dialógicas que os constituem.

Portanto, todo dialogismo implica relações entre enunciados. Um enunciado se constitui em relação aos enunciados que o precedem e que o sucedem na cadeia de comunicação. Todo enunciado solicita uma resposta, espera sempre uma compreensão responsiva ativa, seja ela uma concordância ou uma refutação.

Foram consideradas, também, as contribuições de Rojo (2009) sobre as capacidades de leitura: as capacidades de decodificação, que englobam o domínio das convenções gráficas e suas relações, ou seja, capacidades aprendidas no processo de alfabetização; as capacidades de compreensão, que se referem a uma sequência de capacidades que envolvem o antes, o durante e o depois da leitura; e as capacidades de apreciação e réplica do leitor em relação ao texto, que se referem a uma sequência de capacidades que já envolvem a interação do leitor, assumindo uma posição na leitura.

Identificou-se, com base na intervenção mediadora do professor no processo de compreensão leitora, as seguintes capacidades: ativação do conhecimento prévio dos alunos, comparação de informações, ativação de conhecimentos do mundo, produção de inferências locais e apreciações relativas a valores éticos e/ou políticos.

Nas S.D, o aspecto persuasivo, dialógico, favoreceu a atividade mental e, consequentemente, propiciou a construção de conhecimento. Desse modo, como defendido por Geraldi (2006), a produção de textos orais supera uma forma de apenas mostrar o que se aprendeu, para se transformar em um trabalho discursivo envolvendo alunos e professores.

Finalmente, como identificado neste estudo, as disciplinas do currículo escolar podem contribuir para a formação de leitores competentes. Para tanto, será importante que os professores criem contextos que mobilizem os alunos para maior participação nos discursos em sala de aula, bem como questionando suas posições, negociando encaminhamentos, dentre outros.

Como postulado por Bakhtin e Voloschinov (2004), a linguagem está sempre "povoada" de interações de outrem. Daí, defender-se maior consciência de 
natureza pluridiscursiva da língua e da linguagem e que o trabalho do professor contemple e valorize a palavra persuasiva. (BAKHTIN, 1975).

Concluindo, este trabalho não se encerra aqui, novos campos de investigação se abrem sobre as práticas de leitura, como também sobre a avaliação das capacidades de linguagem a serem desenvolvidas no currículo escolar, a fim de abrir novas possibilidades de pensar o ensino de leitura em outras áreas do conhecimento.

\section{REFERÊNCIAS}

BARTON, D. I think they know that: aspects of English language work in primary classroom. Nottingham Linguistic Curricular, n. 5, p. 22-34, 1976.

BAKHTIN, M. Questões de literatura e de estética: a teoria do romance. São Paulo: Hucitec, 1975.

BAKHTIN, M. Os gêneros do discurso: estética da criação verbal. 2. ed. São Paulo: Martins Fontes, 1979.

BAKHTIN, M.; VOLOCHINOV. N. V. Marxismo e filosofia da linguagem. São Paulo: Hucitec, 2004.

FAILLA, Z. (Org.). Retratos da Leitura no Brasil 3. São Paulo: Imprensa Oficial: Instituto Pró-Livro, 2012.

FERNANDES, C. O Fracasso escolar e escola em ciclos: tecendo relações históricas, políticas e sociais. ANPEd, GT: educação fundamental, Caxambu, n. 13, 2004.

GERALDI, J. W. (Org.). O texto na sala de aula. São Paulo: Ática, 2006.

GOMES. S. S. Práticas de Avaliação da Aprendizagem e sua Relação com a Formação Continuada de Professores no Cotidiano do Trabalho Escolar. Estudos em Avaliação Educacional. Fundação Carlos Chagas, v. 16, n. 32, jul./dez. 2005, p. 111-144.

GOMES, S. S. Um olhar sobre as práticas de avaliação na escola. Belo Horizonte: Mazza Edições, 2014.

LÁZARO, A.; BEAUCHAMP, J. A Escola e a formação de leitores. In: AMORIM, G. (Org.). Retratos da leitura no Brasil. São Paulo: Imp. Oficial: Instituto Pró-Livro, 2008. p.73-94.

LEAL, T. F.; MORAIS, A. G. A argumentação em textos escritos: a criança e a escola. Belo Horizonte: Autêntica, 2004. 
ROJO, R. H. R. Letramentos múltiplos, escola e inclusão social. São Paulo: Parábola Editorial, 2009.

ROSSI, M. M. C. Imagens que falam: leitura da arte na escola. Porto Alegre: Mediação, 2003.

SCHNEUWLY, B.; DOLZ, J. Os gêneros escolares: das práticas de linguagem aos objetos de ensino. In: ROJO, R.; CORDEIRO, G. S. (Trad. e Org.). Gêneros orais e escritos na escola. São Paulo: Mercado de Letras, 2004. p. 71-91.

VYGOTSKY, L. S. A formação social da mente. São Paulo: Martins Fontes, 1930.

VYGOTSKY, L. S. Pensamento e linguagem. São Paulo: Martins Fontes, 1934.

Texto recebido em 13 de abril de 2016. Texto aprovado em 15 de agosto de 2016. 